\title{
SHORTENED PEGINTERFERON AND RIBAVIRIN TREATMENT FOR CHRONIC HEPATITIS C
}

Debbie Hartwell

e-mail:d.hartwell@soton.ac.uk
Jeremy Jones, Louise Baxter, Jonathan Shepherd

Southampton Health Technology Assessments (entre (SHTAC), University of Southampton, First

Floor Epsilon House, Enterprise Road, Southampton Science Park, Southampton S016 7NS

Background: Peginterferon alfa and ribavirin combination therapy is an effective treatment for many patients with chronic hepatitis ( virus (HCV). Reducing the length of treatment may be advantageous. We performed a systematic review and economic evaluation to assess shorter treatment duration of this regimen.

Methods: We searched fourteen bibliographic databases (including The Cochrane Library, Medline, and Embase) from 2000 to 0ctober 2009 and consulted experts and drug manufacturers. Eligible articles were randomized controlled trials (RCTs) selected according to predefined criteria. We undertook an economic evaluation to assess the cost-effectiveness of shortened treatment versus standard treatment in the UK.

Results: Six trials were included. In the sub-group of patients who had low viral load (LVL) and a rapid virological response (RVR), there were no statistically significant differences in sustained virological response (SVR) rates between patients who received standard treatment (range, 83 percent to 100 percent) and those who received shortened courses (range 84 percent to 96 percent) (24 weeks for genotype 1, 16 weeks for genotype 2/3). Shortened treatment resulted in cost savings, but in some scenarios also resulted in poorer outcome, compared with standard treatment. This requires a judgment to be made on the value of the quality-adjusted life-year loss resulting from adopting a shorter treatment regimen, if shorter treatment is associated with a lower SVR than standard treatment duration.

Conclusions: For chronic HCV patients who have LVL and achieve an RVR, shortened peginterferon and ribavirin combination therapy could be considered as a viable treatment option.

Keywords: Chronic hepatitis C, Cost-effectiveness, Economic evaluation, Peginterferon alfa, Systematic review

Infection with hepatitis $\mathrm{C}$ virus (HCV) is a significant public health problem. The estimated global prevalence of chronic $\mathrm{HCV}$ is around $2-3$ percent, corresponding to approximately 130-170 million people $(23 ; 24)$. Peginterferon alfa and ribavirin combination therapy is currently the standard treatment for chronic HCV in a number of countries $(4 ; 7 ; 15 ; 16)$. Successful treatment is considered to be attainment of a sustained virological response (SVR), defined as undetectable serum HCV RNA 6 months after cessation of treatment. In recent years, one of the key aims of the management of HCV is to maximize the likelihood of an SVR while minimizing potential adverse effects of treatment. The adverse effects associated with interferon based anti-viral treatment (e.g., flu-like symptoms, nau-

We thank members of our advisory group panel who provided expert clinical advice and comments on a draft of the full report, and Karen Welch (Information Scientist, SHTAC) for generating and running the literature searches for the full report. This work was completed as part of an update review funded by the UK National Institute for Health Research (NIHR) Health Technology Assessment Programme (project number 08/98/01) and commissioned on behalf of the National Institute for Health and Clinical Excellence (NICE). It has been used in the NICE technology appraisal process (http://guidance.nice.org.uk/TA200/Guidance/pdf/English). The full report evaluating treatment in all the patient subgroups affected by the licence extensions has been published in Health Technology Assessment 2011;15(17) (see the HTA Programme Web site [www.hta.ac.uk] for further project information). The views and opinions expressed therein are those of the authors and do not necessarily reflect those of the NIHR HTA Programme. Ethics approval was not required. sea, vomiting, depression) and ribavirin (e.g., anemia) can be significant, and some patients describe it as a very unpleasant experience, disrupting their social and family life, and in some cases impairing their ability to work. Extensions to the original licenses for the two available peginterferons ( $\alpha-2 \mathrm{a}$ and $\alpha-2 \mathrm{~b})$ allow patients who have a low viral load (LVL) and achieve a rapid virological response (RVR) (negative qualitative HCV RNA) at 4 weeks treatment to receive shortened treatment courses. Sparing patients the potential adverse effects through shorter, effective treatment courses will make therapy more tolerable, and may have the additional advantage of encouraging more people with suspected HCV to present for diagnosis, assessment and treatment. It may also be a cost-effective option, although this requires further empirical investigation.

We assessed the clinical and cost-effectiveness of peginterferon alfa and ribavirin for the treatment of chronic HCV in patients eligible for shortened treatment to help inform UK policy recommendations (18). It is part of a larger review evaluating treatment in several patient sub-groups affected by the license extensions (8) and also further updates and extends our previously published research into the clinical and cost-effectiveness of treatments for chronic HCV $(9 ; 19)$.

\section{MEHODS}

A sensitive literature search was applied to fourteen electronic bibliographic databases (including The Cochrane Library, 
Medline and Embase) from 2000 to October 2009. Key hepatitis $\mathrm{C}$ resources and symposia, bibliographies, and industry submissions were also searched and clinical experts were contacted.

Randomized controlled trials (RCTs) of adults with chronic $\mathrm{HCV}$ who were eligible for shortened treatment (i.e., with baseline LVL and an RVR at week 4 of treatment) were included. Studies had to evaluate standard peginterferon alfa and ribavirin combination therapy (or monotherapy for those unable to tolerate ribavirin) compared with shortened duration courses of combination therapy ( 24 weeks for genotype $1 ; 16$ weeks for genotype $2 / 3$, as per the licenses). Outcomes included measures of virological response (RVR and SVR), relapse rate, and adverse events. In addition, full economic evaluations and studies of health-related quality of life (HRQoL) were sought for this sub-group of patients.

Inclusion criteria were applied, data were extracted and quality was assessed by two reviewers independently, with any differences in opinion resolved through discussion. Methodological quality was evaluated using standard criteria (2) and the risk of bias was assessed following the principles of Cochrane methodology (10). Data were synthesized through a narrative review. A meta-analysis was not undertaken due to differences in the drug regimens, and because outcome data were based on relatively small sub-groups of the randomized patients. Further details on the search strategy and the systematic methods used to inform the review are presented in the full research report (8).

\section{Description of the Model}

A published Markov model (20) was adapted to estimate the cost-effectiveness of a shortened course of peginterferon $\alpha$ $2 \mathrm{a}$ or peginterferon $\alpha-2 \mathrm{~b}$ combination therapy, compared with standard duration of treatment, for the treatment of chronic $\mathrm{HCV}$ in eligible patients. The model had a lifetime horizon and a cycle length of 1 year, with a half-cycle correction applied. The perspective was that of the UK National Health Service (NHS) and personal and social services (PSS), and a discount rate of 3.5 percent was applied to both future costs and benefits.

Patients have a mean age at entry to the model of 40 , and 70 percent of the cohort is male $(6 ; 14)$. The distribution of patients across stages of liver disease was taken from a clinical audit of patients at a liver unit (6): 46 percent of these had mild disease, 44 percent moderate disease, and 10 percent cirrhosis.

SVR estimates for patients receiving shortened courses of treatment were taken from trials included in our systematic review of clinical effectiveness. Transition probabilities for progressive liver disease were based on data reported in an RCT of treatment of patients with mild hepatitis C (26) (for progression from mild to moderate liver disease, and from moderate disease to compensated cirrhosis), from the literature on natural history and previous economic evaluations (further details are presented in the full research report [8]). Patients with mild or moderate liver disease, or compensated cirrhosis, faced the same mortality risk as the general population, whereas patients with more severe disease faced higher mortality rates, related to their stage of liver disease (8).

Health state utilities for patients with chronic HCV and associated liver disease, assessed using the EuroQol-5D in the mild hepatitis C RCT (26) and valued using a general population tariff (5), were applied in the model (see Supplementary Table 1, which can be viewed online at www.journals.cambridge.org/thc2012049) (20). Utilities were reduced during the year in which treatment occurred to take account of the adverse effect of anti-viral treatment on HRQoL.

Drug unit costs were taken from the British National Formulary (September 2009). For patients receiving peginterferon $\alpha-2 \mathrm{a}$ and ribavirin therapy, the total drug costs estimated in genotype 1 patients were GBP5,712 and GBP11,425 for 24 weeks and 48 weeks treatment respectively. For genotype $2 / 3$ patients receiving this drug combination, the cost was GBP3,216 for 16 weeks and GBP4,824 for 24 weeks. For patients receiving peginterferon $\alpha-2 \mathrm{~b}$ and ribavirin, the total drug costs were GBP5,540 for 24 weeks and GBP11,081 for 48 weeks of treatment (genotype 1 only).

Costs of monitoring and additional patient management while on anti-viral treatment were based on those used in our previous economic evaluation (20). Health state costs for SVR, chronic HCV, compensated cirrhosis, decompensated cirrhosis, and hepatocellular carcinoma have been taken from an observational study conducted alongside the mild hepatitis C RCT (26), and are reported in Supplementary Table 2, which can be viewed online at www.journals.cambridge.org/thc2012050. Liver transplantation costs were taken from a UK Department of Health funded study (12). The base year for costs in the analysis is $2007 / 8$ (3).

Deterministic base case results, in terms of total and incremental costs and quality-adjusted life-years (QALYs) for each strategy, and incremental cost per QALY gained, are reported. Due to difficulties in interpreting incremental cost-effectiveness ratios (ICERs) and applying standard cost-effectiveness decision rules where interventions are cost-saving and QALYreducing (see Supplementary Appendix, which can be viewed online at www.journals.cambridge.org/thc2012051), we also report results in terms of incremental net monetary benefits (INMB) $(21 ; 22)$.

\section{Evaluation of Uncertainty}

Univariate sensitivity analysis was used to address particular areas of uncertainty in the model related to structure and methodological assumptions as well as transition probabilities around which there is considerable uncertainty.

Parameter uncertainty was addressed using probabilistic sensitivity analysis (PSA). The probability of achieving SVR, health state costs, health state utility values, and transition probabilities for the natural history parameters were sampled using probability distributions assigned to the point estimates used in 


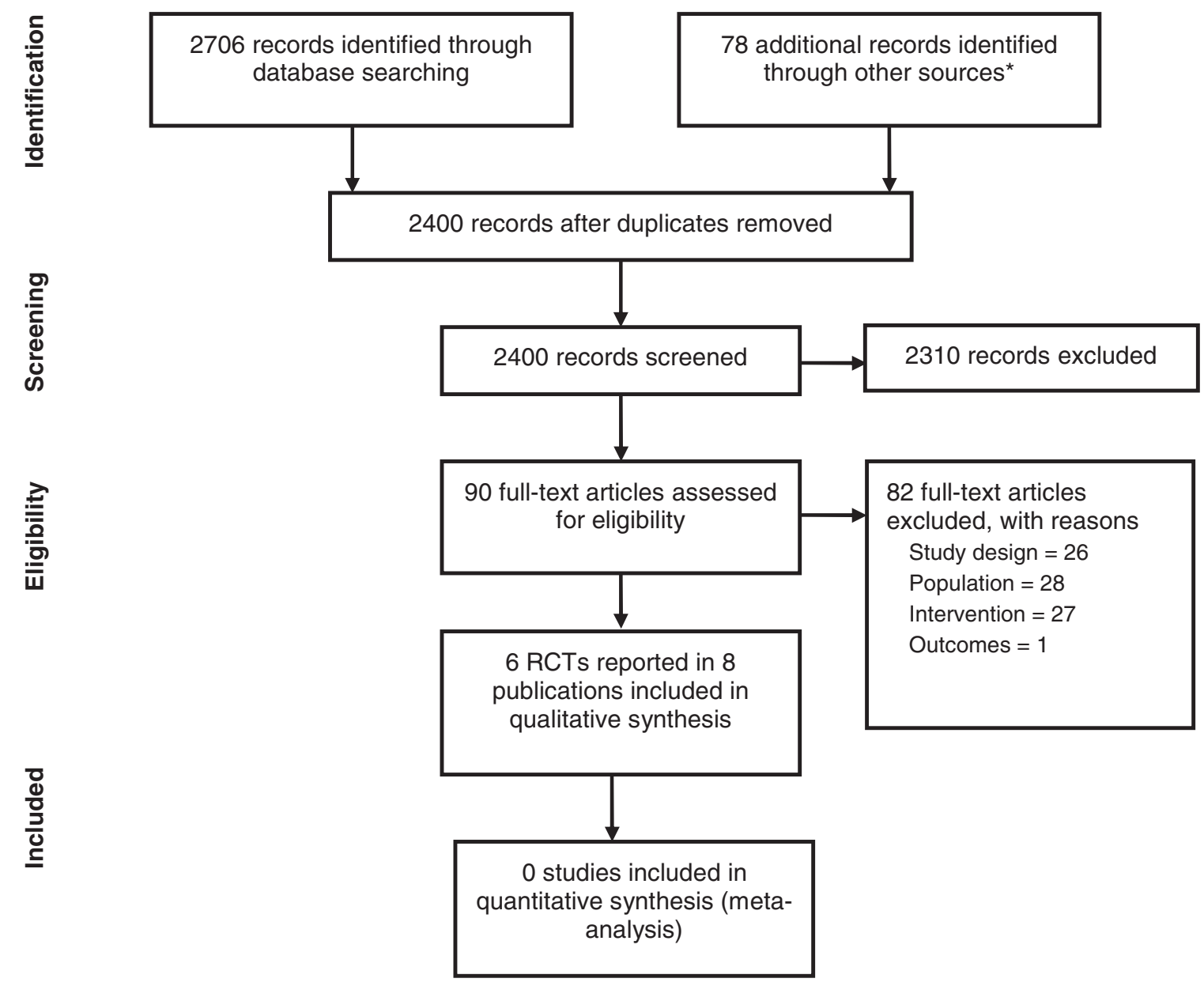

Figure 1. Prisma flow chart. The asterisk indicates key hepatitis C symposia, conference abstracts, and bibliographies. RCTs, randomized controlled trials.

the base case analysis. Characteristics of the distributions used for sampling are reported in full elsewhere (8).

\section{RESULTS}

\section{Quantity and Quality of Research}

After screening (Figure 1), six RCTs were included $(1 ; 11 ; 13 ; 25 ; 27 ; 28)$. Shortened treatment in patients with genotype 1 was evaluated in four trials $(1 ; 11 ; 13 ; 27)$, genotype 2 in one trial (28), and genotype $2 / 3$ in one trial (25). In five of the trials, patients had LVL $(<400,000 \mathrm{IU} / \mathrm{ml}(27)$ or $\leq 800,000$ $\mathrm{IU} / \mathrm{ml}(1 ; 11 ; 25 ; 28))$ at baseline (based on mean viral load). In the sixth trial (Mangia and colleagues (13), only 24 percent of patients had LVL at baseline $(<400,000 \mathrm{IU} / \mathrm{ml})$, but the trial was included because results were reported for the sub-group of patients with an LVL and RVR. A comparison of baseline characteristics of the RVR/LVL subgroups was not presented by the trials, although within studies the main treatment groups were similar at baseline on demographic, biochemical, and virological characteristics. Methodological reporting and quality varied between the included studies, although quality was judged to be good overall. The possibility of detection bias was deemed minimal as the objective "hard" end point of SVR is unlikely to be influenced by a lack of blinding. However, there may be a risk of selection bias in four trials where it was unclear if there was adequate concealment of allocation to treatment groups. Table 1 shows the primary outcome summaries of the included trials. The key characteristics, methodological quality, and some secondary outcome measures can be seen in Supplementary Table 3, which can be viewed online at www.journals.cambridge.org/thc2012052.

\section{CLINICAL EFFECTIVENESS RESULTS}

\section{Sustained Virological Response}

In the sub-group of patients with LVL who attained an RVR, SVR rates were comparable between groups who received the standard duration of treatment (range, 83 percent to 100 percent) and shortened courses (range 84 percent to 96 percent), with no statistically significant differences between treatment arms. In addition, SVRs were broadly similar regardless of genotype with the exception of one trial of genotype 1 patients where SVRs 
Table 1. Clinical Effectiveness: Primary Outcome and Adverse Events

\begin{tabular}{|c|c|c|c|}
\hline Study details & Group 1 & Group 2 & $p$ value \\
\hline $\begin{array}{l}\text { Berg et al., } 2009 \text { (1) } \\
\text { Genotype } 1\end{array}$ & $\begin{array}{l}\text { PEG } \alpha-2 b+\text { RBV } \\
48 w k s(n=225)\end{array}$ & $\begin{array}{l}\text { PEG } \alpha-2 b+R B V \\
24 w k s(n=28)\end{array}$ & \\
\hline $\begin{array}{l}\text { SVR by RVR and LVL }(\leq 800,000 \mathrm{IU} / \mathrm{ml})^{a} \\
\text { SVR by RVRb } \\
\text { Dose discontinuation for any AE } \\
\text { Serious adverse event }\end{array}$ & $\begin{array}{l}75 \%(3 / 4) \\
42 \%(8 / 19) \\
3 \% \\
6.6 \%\end{array}$ & $\begin{array}{l}69 \%(11 / 16) \\
57 \%(16 / 28) \\
2 \% \\
2.6 \%\end{array}$ & $\begin{array}{l}\text { Not reported } \\
\text { Not reported } \\
\text { Not statistically tested } \\
\text { Not statistically tested }\end{array}$ \\
\hline $\begin{array}{l}\text { Mangia et al., } 2008 \text { (13) } \\
\text { Genotype 1 }\end{array}$ & $\begin{array}{l}\text { PEG } \alpha-2 a \text { or } \alpha-2 b+R B V \\
48 w k s(n=237)\end{array}$ & $\begin{array}{l}\text { PEG } \alpha-2 a \text { or } \alpha-2 b+R B V, \\
24 w k s^{c}(n=123)\end{array}$ & \\
\hline $\begin{array}{l}\text { SVR by RVR and LVL ( }<400,000 \mathrm{IU} / \mathrm{ml}) \\
\text { Dose discontinuation for any AE }\end{array}$ & $\begin{array}{l}83.3 \%(20 / 24) \\
7 \%\end{array}$ & $\begin{array}{l}84.4 \%(38 / 45) \\
\text { Only reported for whole of variable } \\
\quad \text { treatment group (not } 24 \text { wks group only) }\end{array}$ & $\begin{array}{l}p=0.83 \\
\text { Not reported }\end{array}$ \\
\hline $\begin{array}{l}\text { Liv et al., } 2008 \text { (11) } \\
\text { Genotype } 1\end{array}$ & $\begin{array}{l}\text { PEG } \alpha-2 a+\text { RBV } \\
24 \text { wks }(n=154)\end{array}$ & $\begin{array}{l}\text { PEG } \alpha-2 a+\text { RBV } \\
48 \text { wks }(n=154)\end{array}$ & \\
\hline $\begin{array}{l}\text { SVR by RVR and LVL ( }<400,000 \mathrm{IU} / \mathrm{ml}) \\
\text { SVR by RVR and LVL }(<800,000 \mathrm{IU} / \mathrm{ml}) \\
\text { Dose discontinuation for any AE } \\
\text { Serious adverse event } \\
\text { Bodyweight loss ( }>10 \% \text { reduction) }\end{array}$ & $\begin{array}{l}100 \%(42 / 42) \\
100 \%(57 / 57) \\
9 \% \\
3 \% \\
30 \%\end{array}$ & $\begin{array}{l}94 \%(49 / 52) \\
94 \%(69 / 73) \\
4 \% \\
7 \% \\
19 \%\end{array}$ & $\begin{array}{l}p=0.25 \\
p=0.13 \\
\text { Not statistically tested } \\
\text { Not statistically tested } \\
p=0.03\end{array}$ \\
\hline $\begin{array}{l}\text { Yu et al., } 2008 \text { (27) } \\
\text { Genotype } 1\end{array}$ & $\begin{array}{l}\text { PEG } \alpha-2 a+R B V \\
24 \text { wks }(n=100)\end{array}$ & $\begin{array}{l}\text { PEG } \alpha-2 a+\text { RBV } \\
48 \text { wks }(n=100)\end{array}$ & \\
\hline $\begin{array}{l}\text { Dose discontinuation - total } \\
\text { - for any AE } \\
\text { - for other reason } \\
\text { Serious adverse event }\end{array}$ & $\begin{array}{l}10 \% \\
8 \% \\
2 \% \\
1 \%\end{array}$ & $\begin{array}{l}96.4 \%(27 / 28) \\
3 \% \\
3 \% \\
0 \\
1 \%\end{array}$ & $\begin{array}{l}p=1.000 \text {, difference } \\
-3.6 \%(95 \% \text { Cl } \\
-14.3 \% \text { to }-0.6 \%) \\
p=0.045 \\
\text { Not statistically tested } \\
\text { Not statistically tested } \\
\text { Not statistically tested }\end{array}$ \\
\hline $\begin{array}{l}\text { Yu et al., } 2007 \text { (28) } \\
\text { Genotype } 2\end{array}$ & $\begin{array}{l}\text { PEG } \alpha-2 a+R B V \\
24 \text { wks }(n=100)\end{array}$ & $\begin{array}{l}\text { PEG } \alpha-2 a+R B V \\
16 \text { wks }(n=50)\end{array}$ & \\
\hline $\begin{array}{l}\text { SVR by RVRd } \\
\text { Dose discontinuation - total } \\
\text { - for any AE } \\
\text { Serious adverse event } \\
\text { Alopecia }\end{array}$ & $\begin{array}{l}98 \%(85 / 87) \\
1 \% \\
1 \% \\
0 \\
49 \%\end{array}$ & $\begin{array}{l}100 \%(43 / 43) \\
0 \\
0 \\
0 \\
20 \%\end{array}$ & $\begin{array}{l}p=1 \\
\text { Not statistically tested } \\
\text { Not statistically tested } \\
\text { Not statistically tested } \\
p=0.001\end{array}$ \\
\hline
\end{tabular}


Hartwell et al.

Table 1. Continued.

\begin{tabular}{|c|c|c|c|}
\hline Study details & Group 1 & Group 2 & $p$ value \\
\hline $\begin{array}{l}\text { von Wagner et al., } 2005 \text { (25) } \\
\text { Genotype } 2 \text { or } 3\end{array}$ & $\begin{array}{l}\text { PEG } \alpha-2 a+\text { RBV } \\
16 \text { wks }(n=71)\end{array}$ & $\begin{array}{l}\text { PEG } \alpha-2 a+\text { RBV } \\
24 \text { wks (RVR) }(n=71)\end{array}$ & \\
\hline $\begin{array}{l}\text { SVR by RVR and LVL }(\leq 800,000 \mathrm{IU} / \mathrm{ml}) \\
\text { Dose discontinuation - total } \\
\text { - for any AE } \\
\text { - for other reason }\end{array}$ & $\begin{array}{l}87 \%(27 / 31) \\
8 \% \\
1 \% \\
7 \%\end{array}$ & $\begin{array}{l}94 \%(33 / 35) \\
1 \% \\
1 \% \\
0\end{array}$ & $\begin{array}{l}p=\text { not reported } \\
\text { Not statistically tested } \\
\text { Not statistically tested } \\
\text { Not statistically tested }\end{array}$ \\
\hline \multicolumn{4}{|c|}{ 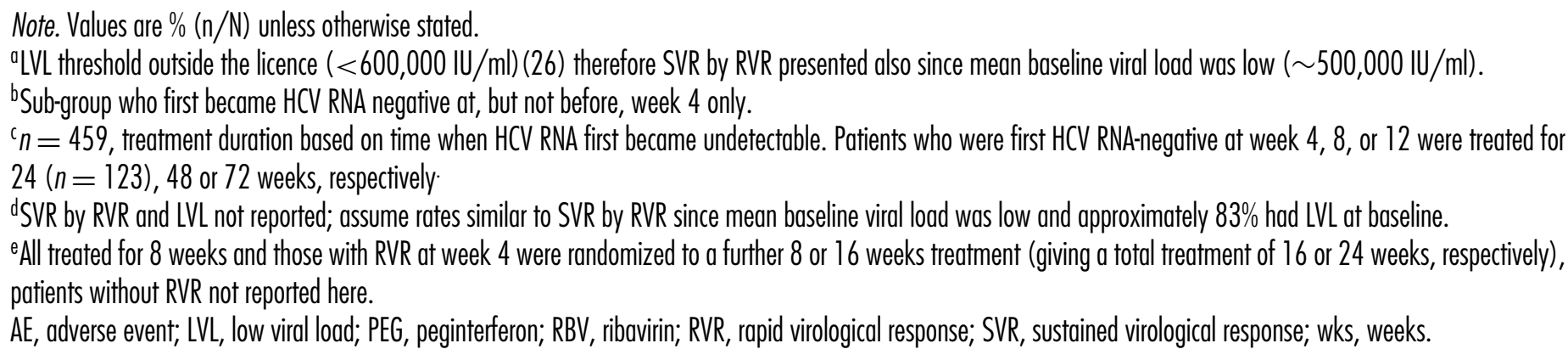 } \\
\hline
\end{tabular}

were noticeably lower for standard compared with shortened treatment (42 percent versus 57 percent, respectively) (1). This may be a consequence of the study design where the SVR rates presented are for those patients who first became HCV RNAnegative at week 4 and do not include those who also became negative during weeks 1 to 3 as in the other trials. It should also be noted that patient numbers in the LVL/RVR sub-groups were relatively small and none of the trials were powered for this sub-group analysis.

\section{Rapid Virological Response}

For both genotype 1 and genotype $2 / 3$ patients, rates of RVR were observed to be similar between groups who received standard treatment (range, 26 percent to 63 percent) versus those who received shortened courses (range, 27 percent to 68 percent) (not statistically significant in two trials; not statistically tested in four trials). There was a large range in reported RVR rates between the studies, but the proportion of patients achieving an RVR was generally higher in those with genotype $2 / 3$ than in those with genotype 1 . The low RVR rates in the trial by Mangia and colleagues (13) may be due to the smaller proportion of patients ( 24 percent) having LVL at baseline.

\section{Relapse Rate}

In the one trial (27) reporting virological relapse rates in the LVL/RVR sub-group, rates were low and not statistically significantly different between those treated for 24 versus 48 weeks (3.6 percent versus 0 , respectively, difference 3.6 percent ( 95 percent confidence interval, -7.2 percent to 6.6 percent), $p=$ $1.000)$.

\section{Adverse Events}

Adverse events were reported for treatment groups as a whole, and the reporting of statistical tests by the trials varied. The most frequently occurring adverse events were similar across all the trials and included flu-like symptoms, insomnia, anorexia, dermatological symptoms, and alopecia. On the whole, the frequency of adverse events were not statistically different between treatment arms (where reported), although there was a trend for a lower incidence of adverse events and fewer dose discontinuations in patients receiving a shortened treatment regimen.

\section{RESULTS OF ECONOMIC EVALUATION}

Costs and outcomes modelled for patients eligible for shortened duration of treatment with peginterferon and ribavirin combination therapy are presented in Table 2 . Separate analyses are presented for each trial included in the systematic review of clinical effectiveness, as meta-analysis of RCTs was not considered appropriate (discussed earlier).

\section{Peginterferon $\alpha$-2a}

For genotype 1 patients, shortened duration ( 24 weeks) of treatment is associated with a reduction in total costs between approximately GBP4,800 and GBP5,200. While the small reduction in SVR associated with shortened treatment duration results in some additional costs from disease progression for this cohort, these are not sufficient to offset the cost reduction arising from the shorter duration of treatment. The reduction in treatment-related adverse events expected for shorter duration of treatment does not fully offset the reduction in QALYs due 
Table 2. Base Case Cost-Effectiveness for Shortened Treatment Duration Using Peginterferon ( $\alpha$-2a or $\alpha$-2b) and Ribavirin Combination Therapy

\begin{tabular}{|c|c|c|c|c|c|c|c|c|c|c|}
\hline \multirow[b]{2}{*}{ RCT } & \multirow[b]{2}{*}{$\begin{array}{l}\text { Patient group and } \\
\text { treatment length }\end{array}$} & \multicolumn{2}{|c|}{ Standard treatment } & \multicolumn{2}{|c|}{$\begin{array}{l}\text { Shortened } \\
\text { treatment }\end{array}$} & \multicolumn{2}{|c|}{ Incremental } & \multirow[b]{2}{*}{$\begin{array}{l}\text { ICER (GBP per } \\
\text { QALY gained) }\end{array}$} & \multicolumn{2}{|c|}{ INMB (GBP) } \\
\hline & & $\begin{array}{l}\text { Cost } \\
\text { (GBP) }\end{array}$ & $\begin{array}{l}\text { Outcome } \\
\text { (QALYS) }\end{array}$ & $\begin{array}{l}\text { Cost } \\
\text { (GBP) }\end{array}$ & $\begin{array}{l}\text { Outcome } \\
\text { (QALYS) }\end{array}$ & $\begin{array}{l}\text { Cost } \\
\text { (GBP) }\end{array}$ & $\begin{array}{l}\text { Outcome } \\
\text { (QALYS) }\end{array}$ & & $\begin{array}{c}\lambda= \\
20,000\end{array}$ & $\begin{array}{c}\lambda= \\
30,000\end{array}$ \\
\hline \multicolumn{11}{|l|}{ Peginterferon $\alpha$-2a and ribavirin } \\
\hline Liv et al, 2008 (11) & $\begin{array}{l}\text { Genotype } 1 \\
\quad 48 \text { weeks vs. } 24 \text { weeks }\end{array}$ & 14,206 & 15.68 & 9,399 & 15.54 & $-4,807$ & -0.14 & 34,510 & 2,021 & 628 \\
\hline Yu et al., 2008 (27) & $\begin{array}{l}\text { Genotype } 1 \\
\quad 48 \text { weeks vs. } 24 \text { weeks }\end{array}$ & 14,206 & 15.68 & 8,994 & 15.60 & $-5,212$ & -0.08 & 64,880 & 3,605 & 2,802 \\
\hline Yu et al., 2007 (28) & $\begin{array}{l}\text { Genotype } 2 \\
24 \text { weeks vs. } 16 \text { weeks }\end{array}$ & 7,834 & 15.64 & 5,728 & 15.72 & $-2,107$ & 0.08 & Shortened duration dominates & 3,727 & 4,537 \\
\hline von Wagner et al., 2005 (25) & $\begin{array}{l}\text { Genotype } 2 \text { or } 3 \\
24 \text { weeks vs. } 16 \text { weeks }\end{array}$ & 10,089 & 15.31 & 6,943 & 15.54 & $-3,146$ & 0.23 & Shortened duration dominates & 7,788 & 10,109 \\
\hline
\end{tabular}

Peginterferon $\alpha$-2b and ribavirin

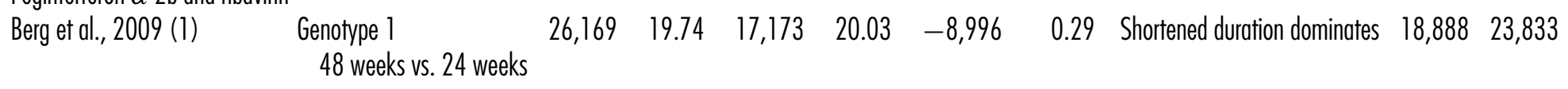

GBP, Great Britain pounds; ICER, incremental cost-effectiveness ratio; INMB, incremental net monetary benefits; RCT, randomized controlled trial; QALY, quality-adjusted life-year.

to a larger proportion of patients experiencing progressive liver disease in the cohort of patients receiving shortened duration of treatment. Hence, shortened treatment duration is associated with an overall QALY loss (between 0.08 and 0.14). The ICERs range from GBP34,150 to GBP64,880. Given that both incremental costs and QALYs are negative, the conventional cost-effectiveness decision rule (where a technology should be adopted if the ICER is below a given threshold value) does not apply (see Supplementary Appendix). The INMB are positive, indicating that shortened duration of treatment with peginterferon $\alpha-2 \mathrm{a}$ combination therapy is a cost-effective option for genotype 1 patients with LVL at baseline and who achieve RVR.

For patients with genotype 2 or 3 receiving the shortened course, there was a reduction in total costs of between approximately GBP2,100 and GBP3,150. The higher SVR for the shorter duration of treatment also results in a gain in total QALYs of between 0.08 and 0.23 , which leads to shortened treatment dominating standard duration treatment.

\section{Peginterferon $\alpha-2 b$}

Shorter duration of treatment was associated with a reduction in total costs of approximately GBP9,000. There were also small reductions in total costs associated with a reduced risk of disease progression in this cohort. In addition, there was a QALY gain of 0.49 due to a higher SVR in shortened treatment duration, so this strategy dominated standard treatment.

\section{Deterministic Sensitivity Analysis}

A deterministic sensitivity analysis (DSA) was undertaken, which consisted predominantly of univariate sensitivity analyses, where one parameter is varied at a time. These analyses encompassed structural uncertainties in the model, uncertainties over the composition of the baseline cohort and uncertainty over parameter values. The DSA suggested that the results in peginterferon $\alpha$-2a for all genotypes, and peginterferon $\alpha-2 b$ for genotype 1 were generally robust to changes in structural assumptions and input parameter values. Reducing drug acquisition costs has the effect of reducing the cost-effectiveness of shortened treatment duration, as it reduces the cost saving between standard and shortened treatment duration while the outcome difference is unchanged. Incremental costs and QALYs were most sensitive to changes in assumptions regarding the baseline characteristics of the patient cohort. In particular, the cost-effectiveness estimates were highly sensitive to the mean starting age and stage of liver disease. The sensitivity analysis suggested that shortened treatment duration was most likely to be cost-effective in older patients and those with less severe liver disease associated with chronic HCV infection. Full results of the DSA are reported elsewhere (8).

Given that some included trials reported potentially counterintuitive results (with shortened treatment duration being more effective, in terms of SVR, than standard duration) we conducted an additional scenario analysis on the impact of the difference in SVR on the cost-effectiveness results, as- 
suming that the SVR for shortened treatment duration is less than or equal to that for standard treatment duration (see Supplementary Table 4, which can be viewed online at www.journals.cambridge.org/thc2012053). This suggested that, where the difference in SVR was small (less than 2 percent), shortened treatment duration may be a highly cost-effective option, particularly for genotype 1 patients. However, as the SVR difference increases, the potential cost savings reduce, and the QALY loss increases rapidly, particularly for genotype 2 or 3 patients.

\section{Probabilistic Sensitivity Analysis}

For genotype 1 patients shortened treatment duration using peginterferon $\alpha$-2a combination therapy had a probability of being cost-effective of 83 percent at a willingness to pay threshold of GBP20,000 per QALY and 59 percent at a willingness to pay threshold of GBP30,000, using efficacy data from the trial reported by Liu and colleagues (11). The equivalent values using efficacy data from the trial reported by Yu and colleagues (27) are 100 percent at both willingness to pay thresholds. For genotypes 2 or 3 patients, the probability of shortened treatment duration using peginterferon $\alpha$-2a combination therapy being cost-effective was 100 percent at both willingness to pay thresholds using efficacy data from either included trial $(25 ; 28)$. Similar results were observed for shortened treatment duration using peginterferon $\alpha-2 \mathrm{~b}$ combination therapy in genotype 1 patients.

\section{DISCUSSION}

The clinical evidence in this systematic review consists of six RCTs of reasonable methodological quality. The data suggest that chronic HCV patients who have LVL at baseline and who achieve an RVR at 4 weeks of treatment can be treated with shortened courses of therapy ( 24 weeks for genotype 1 ; 16 weeks for genotype 2/3) and achieve rates of SVR that are comparable to those who receive the standard duration of treatment. In addition, there was a trend for a lower incidence of adverse events and fewer dose discontinuations in those receiving a shortened treatment regimen, although some were not tested for statistical significance. Thus, if patients with specific genotypes meeting the license criteria receive shortened courses of anti-viral treatment, they may benefit in terms of reduced exposure to adverse effects which can be unpleasant and may have a considerable impact on a person's day to day life, as well as that of family and carers. However, it is worth noting that some patients may be willing to tolerate the adverse effects of treatment and prefer to have the full course of therapy if it may maximize the chance of achieving an SVR, or reduce the possibility of relapse following treatment. Although patients receiving shortened treatment courses were significantly less likely to relapse compared with those receiving standard duration treatment, this was only reported in the sub-group of patients with LVL and RVR in one trial. More data would be needed on relapse rates before there is any certainty as to whether shortening treatment would not put patients at higher risk of relapsing at a later date. Furthermore, it should be noted that SVRs according to baseline LVL and RVR were based on patient sub-groups as opposed to all randomized patients. It is unlikely that the RCTs were statistically powered in respect of these sub-groups, so caution is advised in interpretation of the data.

In the absence of relevant cost-effectiveness papers, a previously published Markov model was adapted to estimate the cost-effectiveness of shortened treatment. Shortened duration of treatment for genotype 1 patients with LVL/RVR, receiving peginterferon $\alpha-2 \mathrm{a}$, reduced total costs by approximately one third, but resulted in a slightly poorer outcome (QALYs reduced by approximately 1 percent). The ICERs were positive (ranging from GBP34,000 to GBP65,000). Because both incremental costs and QALYs are negative, the cost-effectiveness results should be interpreted in terms of the savings required for society to accept the reduced outcome (rather than the more familiar situation in which we are concerned with society's willingness to pay for a given health gain). In this context, conventional cost-effectiveness thresholds (for example, GBP20,000 or GBP30,000 per QALY gained in certain contexts (17)) should be regarded as a minimum, rather than maximum, acceptable value.

Shorter duration of treatment (from 24 to 16 weeks) with peginterferon $\alpha$-2a for genotype 2 and 3 patients reduced total costs by approximately a quarter, and was associated with a better outcome in the included trials. In these scenarios, shortened treatment duration for the sub-group of genotype 2 or 3 patients with LVL and RVR dominated standard duration therapy. Shorter duration of treatment (from 48 to 24 weeks) with peginterferon $\alpha-2 b$ for the sub-group of genotype 1 patients with LVL and RVR was associated with a reduction in costs of approximately GBP9,000. Combined with a QALY gain increase of 0.49 , this resulted in peginterferon $\alpha-2 \mathrm{~b}$ dominating the standard 48 week duration of treatment.

There are some points to take into account when considering the cost-effectiveness aspect of this review. Some of the effectiveness data included in our independent model has been taken from comparatively small trials ( 20 to 40 patients per arm) that were not adequately powered to detect differences in SVR, or were derived from sub-groups of patients in larger trials. In addition, the proportion of patients with different genotypes in multi-national clinical trials is unlikely to be reflective of the genotype distribution in all countries/regions. Hence, the overall SVR is unlikely to provide a good indication of response. As a result, where possible, patient genotypes have been modeled separately adopting commonly used groupings of "difficult to treat" genotypes (genotype 1 and occasionally genotype 4) and more responsive genotypes ( 2 and 3 ). However, it is not clear how closely these distributions, or the assumed mean age of patients at the start of the model, relate to the characteristics of patients in the sub-groups of patients covered by this assessment. 
The reported outcomes, in terms of SVR, were inconsistent for particular genotypes in included trials (with shortened duration being associated with a lower SVR, than for standard duration, in two trials $(11 ; 27)$ and a higher SVR in one trial (1) for genotype 1 patients) and in some cases appear counter-intuitive (with a higher SVR for shortened duration compared with standard treatment in three included trials) $(1 ; 25 ; 28)$. To address the latter issue, we present a scenario analysis on the impact of the difference in SVR on the cost-effectiveness results, assuming that the SVR for shortened treatment duration is less than or equal to that for standard treatment duration. This suggests that shortened duration is likely to be a cost-effective option where the difference in SVR is small and where the cost saving from shortened treatment duration is greatest (i.e., for genotype 1 patients being treated for 24 rather than 48 weeks).

\section{CONCLUSIONS}

In summary, the clinical trial evidence indicates that patients may be successfully treated with a shorter course of peginterferon alfa and ribavirin combination therapy for 16 weeks (genotype 2/3), or 24 weeks (genotype 1), without compromising SVR rates. However, a judgment is required on the value of the QALY loss that may result from adopting a shorter treatment regimen, if shorter treatment is associated with a lower SVR than standard treatment duration. The results from our model suggest that treatment with peginterferon alfa in the specified sub-groups of patients with LVL and RVR will yield QALY gains without excessive increases in costs and may be costsaving in some situations. Shortened treatment could therefore be considered as a viable treatment option for patients and clinicians alike. Any future RCTs evaluating shortened treatment duration should be adequately designed (e.g., randomized at the point of RVR) and statistically powered to avoid use of patient subgroups. Relapse rates should be reported and measurement of health-related quality of life would inform future cost-effectiveness analyses.

\section{POLICY IMPLICATIONS}

It is recommended that shortened courses of peginterferon and ribavirin combination therapy can be prescribed for those patients who achieve an RVR. When deciding on the duration of combination therapy, clinicians should take into account the licensed indication of the chosen drug (peginterferon alfa-2a or peginterferon alfa-2b), the genotype of the hepatitis $C$ virus, the viral load at the start of treatment, and the response to treatment (as indicated by the viral load).

\section{SUPPLEMENTARY MATERIAL}

Supplementary Table 1:

www.journals.cambridge.org/thc2012049

Supplementary Table 2:

www.journals.cambridge.org/thc2012050
Supplementary Appendix:

www.journals.cambridge.org/thc2012051

Supplementary Table 3:

www.journals.cambridge.org/thc2012052

Supplementary Table 4:

www.journals.cambridge.org/thc2012053

\section{CONTACT INFORMATION}

Debbie Hartwell, Research Fellow; B.Sc. (Hons), Ph.D.

Jeremy Jones, Principal Research Fellow (Health Economics); BA (Hons), M.Sc., Ph.D.

Louise Baxter, Research Fellow (Health Economics); BA (Hons), M.Sc.

Jonathan Shepherd, Principal Research Fellow; BA (Hons), Ph.D.

Southampton Health Technology Assessments Centre (SHTAC), University of Southampton, First Floor Epsilon Science House, Enterprise Road, Southampton Science Park, Southampton SO16 7NS, UK

\section{CONFLITS OF INTEREST}

All authors report they have no potential conflicts of interest.

\section{REFERENCES}

1. Berg T, Weich V, Teuber G, et al. Individualized treatment strategy according to early viral kinetics in hepatitis $\mathrm{C}$ virus type 1 -infected patients. Hepatology. 2009;50:369-377.

2. Centre for Reviews and Dissemination (CRD). Systematic reviews: CRD's guidance for undertaking reviews in health care (3rd ed). York: York Publishing Services Ltd; 2009.

3. Curtis L. Unit costs of health and social care. Canterbury: Personal Social Services Research Unit, University of Kent; 2008.

4. de Bruijne J, Buster EHCJ, Gelderblom HC, et al. Treatment of chronic hepatitis $\mathrm{C}$ virus infection - Dutch national guidelines. Neth $\mathrm{J} \mathrm{Med}$. 2008;66:311-322.

5. Dolan P, Gudex C, Kind P, Williams A. A social tariff for EuroQol: Results from a UK general population survey. Discussion Paper 138. York: Centre for Health Economics, University of York; 1995.

6. Foster GR, Goldin RD, Main J, et al. Management of chronic hepatitis C: Clinical audit of biopsy based management algorithm. BMJ. 1997;315:453-458.

7. Ghany MG, Strader DB, Thomas DL, Seeff LB. Diagnosis, management, and treatment of Hepatitis C: An update. Hepatology. 2009;49:1335-1374.

8. Hartwell D, Jones J, Baxter L, Shepherd J. Peginterferon alfa and ribavirin for chronic hepatitis $\mathrm{C}$ in patients eligible for shortened treatment, retreatment or in HCV/HIV co-infection: A systematic review and economic evaluation. Health Technol Assess. 2011;15:1-204.

9. Hartwell D, Shepherd J. Pegylated and non-pegylated interferon-alfa and ribavirin for the treatment of mild chronic hepatitis $\mathrm{C}$ : A systematic review and meta-analysis. Int J Technol Assess Health Care. 2009;25:56-62.

10. Higgins JPT, Altman DT. Assessing risk of bias in included studies. In: Higgins JPT, Altman DT, eds. Cochrane handbook for systematic reviews of interventions. Version 5.0.1 (updated September 2008). The Cochrane Collaboration; 2008.

11. Liu C-H, Liu C-J, Lin C, et al. Pegylated interferon-alpha-2a plus ribavirin for treatment-naive Asian patients with hepatitis $\mathrm{C}$ virus genotype 
1 infection: A multicenter, randomized controlled trial. Clin Infect Dis. 2008;47:1260-1269.

12. Longworth L, Young T, Ratcliffe J, Bryan S, Buxton M. Economic evaluation of the Transplantation Programme in England and Wales: An assessment of the costs of liver transplantation. Unpublished Report to the Department of Health; 2001.

13. Mangia A, Minerva N, Bacca D, et al. Individualized treatment duration for hepatitis $\mathrm{C}$ genotype 1 patients: A randomized controlled trial. Hepatology. 2008;47:43-50.

14. Mohsen AH, Trent HCV Study Group. The epidemiology of hepatitis C in a UK health regional population of 5.12 million. Gut. 2001;48:707-713.

15. National Institute for Health and Clinical Excellence (NICE). Interferon alfa (pegylated and non-pegylated) and ribavirin for the treatment of chronic hepatitis C. Technology Appraisal Guidance No 75. London: NICE; 2004.

16. National Institute for Health and Clinical Excellence (NICE). Peginterferon alfa and ribavirin for the treatment of mild chronic hepatitis $\mathrm{C}$. Technology Appraisal Guidance No 106. London: NICE; 2006.

17. National Institute for Health and Clinical Excellence (NICE). Guide to the methods of technology appraisal. http://www.nice.org.uk/media/B52/ A7/TAMethodsGuideUpdatesJune2008.pdf. London: NICE; 2008 (accessed August, 2009).

18. National Institute for Health and Clinical Excellence (NICE). Peginterferon alfa and ribavirin for the treatment of chronic hepatitis C: Part-review of NICE technology appraisal guidance TA75 and TA106. Technology Appraisal Guidance No 200. London: NICE; 2010.

19. Shepherd J, Brodin HFT, Cave CB, et al. Clinical- and cost-effectiveness of pegylated interferon alfa in the treatment of chronic hepatitis $\mathrm{C}$ :
A systematic review and economic evaluation. Int J Technol Assess Health Care. 2005;21:47-54.

20. Shepherd J, Jones J, Hartwell D, et al. Interferon alfa (pegylated and non-pegylated) and ribavirin for the treatment of mild chronic hepatitis C: A systematic review and economic evaluation. Health Technol Assess. 2007;11:1-205

21. Stinnett AA, Mullahy J. Net health benefits: A new framework for the analysis of uncertainty in cost effectiveness analysis. Med Decis Making. 2009;18:S68-S80.

22. Tambour M, Zethraeus N, Johannesson M. A note on confidence intervals in cost effectiveness analysis. Int J Technol Assess Health Care. 1998; 14:467-471.

23. The Global Burden Of Hepatitis C Working Group. Global burden of disease (GBD) for hepatitis C. J Clin Pharmacol. 2004;44:20-29.

24. Thomson BJ, Finch RG. Hepatitis C virus infection. Clin Microbiol Infect. 2005; 11:86-94.

25. von Wagner M, Huber M, Berg $T$, et al. Peginterferon-alpha-2a (40KD) and ribavirin for 16 or 24 weeks in patients with genotype 2 or 3 chronic hepatitis C. Gastroenterology. 2005;129:522-527.

26. Wright M, Grieve R, Roberts J, et al. Health benefits of antiviral therapy for mild chronic hepatitis C: Randomised controlled trial and economic evaluation. Health Technol Assess. 2006;10:1-113.

27. Yu M, Dai C, Huang J, et al. Rapid virological response and treatment duration for chronic hepatitis $\mathrm{C}$ genotype 1 patients: A randomized trial. Hepatology. 2008;47:1884-1893.

28. Yu M, Dai C, Huang J, et al. A randomised study of peginterferon and ribavirin for 16 versus 24 weeks in patients with genotype 2 chronic hepatitis C. Gut. 2007;56:553-559. 